\title{
TRANSTERRITORIALIDADE E ANTROPOFAGIA: TERRITORIALIDADES DE TRÂNSITO NUMA PERSPECTIVA BRASILEIRO-LATINO-AMERICANA
}

\author{
ROGÉRIO HAESBAERT* \\ MARCOS MONDARDO**
}

Como no mundo contemporâneo vive-se em múltiplas escalas ao mesmo tempo, uma simultaneidade atroz de eventos, vivenciam-se também, concomitantemente, múltiplos territórios. Ora somos requisitados a nos posicionar perante uma determinada territorialidade, ora perante outra, como se nossos marcos de referência e controle espaciais fossem perpassados por múltiplas escalas de poder e de identidade. Isto resulta em uma geografia complexa, uma realidade multiterritorial (ou mesmo transterritorial) que se busca traduzir em novas concepções, como os termos cosmopolita e "glocal", este significando que os niveis global e local podem estar quase inteiramente confundidos. (Haesbaert, 1996:35-36 [republicado em 2002:121])

Hoje, as identidades que se declaram móveis e múltiplas, podem ser indicação, não de desapropriação e fluidez social, mas antes de uma nova estabilidade, segurança de si e quietismo. A fixidez da identidade só é buscada em momentos de instabilidade e ruptura, de conflito e mudança. (...) a heterogeneidade, o intercâmbio cultural e a diversidade se tornaram agora a identidade autoconsciente da sociedade moderna. (Young, 2005[1995]:5)

* Doutor em Geografia Humana pela USP-São Paulo, com pós-doutorado na Open University-Inglaterra, professor Associado da Universidade Federal Fluminense - UFF (Niterói-RJ).

** Doutorando em Geografia pelo Programa de Pós-Graduação em Geografia da UFF, professor Assistente da Universidade Federal da Bahia/Campus Barreiras. 
Vivemos um tempo de paradoxo e perplexidade que se revela nas mais diversas esferas, do econômico ao político, do cultural ao ambiental. Discursos - e práticas - culturalistas, por exemplo, sobrevalorizam o "vetor identitário" (étnico, religioso, linguístico...) na compreensão e/ou na própria produção dos principais dilemas contemporâneos, ao mesmo tempo em que outros, de fundo algumas vezes economicista, difundem a ideia de um (neo)liberalismo capitalista generalizado (pelo menos o que antecedeu a última crise financeira), como se nada mais nos coubesse senão a aceitação da inexorável homogeneização mercantil-cultural globalizada.

Em meio a isso tudo aparecem "saídas" intermediárias ou, literalmente, "fronteiriças" como aquelas que, em nome do domínio da multiplicidade e da mobilidade, defendem a ideia de uma espécie de "vida no limite" ou no "limiar", num mundo de identidades mescladas, "mestiças", "híbridas" ou "transculturadas" - mundo em que este discurso do hibridismo, muitas vezes, tem um claro sentido de positividade, de tomada de posição a ser defendida e estimulada, aberto à criação de novas identidades ${ }^{1}$, ainda que se apresentando cada vez de maneira mais ambígua e contraditória.

Young, na citação introdutória, revela bem essa ambiguidade, evidenciando uma nova forma de "estabilização" identitária, uma "autoconsciência identitária" moldada no caráter móvel e múltiplo, que não seria, em si mesma, representativa de crise e ruptura, mas de "estabilidade, segurança de si e quietismo". Nos momentos de crise, ao contrário, é que tenderíamos a "fixar" nossas identidades. "Globalização particularizadora" ou "glocalização", "estabilidade na fluidez e na multiplicidade" - eis os jogos ambivalentes com os quais nos deparamos ao analisar os atuais processos de construção identitária.

Imaginemos agora um olhar geográfico sobre a questão, introduzindo aí a dimensão espacial ou, de modo mais estrito, territorial. $\mathrm{Se}$, como indicamos na citação introdutória, os territórios/territorialidades estão sofrendo, igualmente, sensíveis transformações, como se daria essa relação, imanente, entre territórios/territorialidades e construção identitária? Em que sentido essa ambivalência também é alimentada quando a identificação dos grupos sociais se dá relacionada, sobretudo, a um referencial de ordem espacial/territorial tido como cada vez mais

${ }^{1}$ Ou mesmo "para além" das identidades, como defendem autores na coletânea "Para além da identidade: fluxos, movimentos e trânsitos", organizada por Lopes e Bastos (2010). 
móvel? Como se redesenha o jogo entre a diferenciação, a hibridização ${ }^{2}, o$ caráter múltiplo e "liminar" da cultura e os múltiplos territórios ou aquilo que denominamos a multi/transterritorialidade que hoje vivenciamos?

Para a compreensão dos diferentes aspectos dessa complexidade, vista por alguns como emergência de multipertencimentos, por outros como "explosão de identidades" ou, ainda, como momento das multiplicidades, prolifera uma série de termos como hibridismo, multiculturalismo, transculturação, mestiçagem, crioulização, antropofagia, cultura migrante, trânsito identitário, entre outros. $\mathrm{O}$ surgimento desses termos parece ocorrer no momento em que a intensificação da mobilidade e a multiplicidade do espaço configuram um grande potencial para trocas e mesclas culturais que apontam para uma "nova" realidade sócio-espacial, reveladora dessa reinvenção de territorialidades.

Assim, o próprio espaço incorpora feições que valorizam a mobilidade, a multiplicidade e as inter-relações. Massey (2008), por exemplo, considera o espaço como um "produto de inter-relações" e como "a esfera da possibilidade da existência da multiplicidade, no sentido da pluralidade contemporânea (...) na qual distintas trajetórias coexistem" (p. 29), fomentadoras da heterogeneidade. O espaço e, por extensão, o território, vistos não como entidades fechadas, mas abertas, surgem, assim, como possibilidade de encontros/desencontros/confrontos e, principalmente, como trânsito de diferentes sujeitos. Considera-se o espaço na coexistência dessa multiplicidade, estimulada pela crescente mobilidade e pelo intercâmbio de culturas que possibilita, através de práticas (por um lado) mais transculturais e híbridas, a produção de novas formas de identidade e de territorialidade, construídas nesses entrecruzamentos e nessas sobreposições ${ }^{3}$.

\footnotetext{
2 Ou "hibridação", já que os dois termos são aceitos em português.

${ }^{3}$ Num sentido mais amplo, podemos dizer que todas as identidades são também espaciais. Para Massey (1995), identidade e espacialidade são "co-constitutivas". Neste sentido, "não somente existe um paralelo entre a maneira de conceitualizar o espaço e a maneira de conceitualizar entidades/identidades (tais como sujeitos políticos), mas também o espaço é, desde o início, parcela integrante da constituição daquelas subjetividades políticas" (Massey, 2004:9). Propomos, entretanto, distinguir entre essa "dimensão espacial", genérica, de toda identidade e identidades territoriais em sentido estrito, quando uma parcela do espaço se torna claramente referência central para a construção do processo identitário e, assim, de "empoderamento" de um grupo (considerando que toda construção identitária por parte de um grupo é uma estratégia política de afirmação).
} 
Este artigo pretende, também, num nível mais teórico, problematizar a relação entre as concepções de hibridismo/transculturação/antropofagia e multitransterritorialidade. Neste sentido, iniciaremos por alguns pressupostos mais gerais. O primeiro e o mais óbvio é o de que nossas identidades não estão se diluindo com a globalização - podem até, pelo contrário, estar se fortalecendo, em formas tidas como reessencializadas ou, como destacado aqui, sendo recriadas pela própria mobilidade e em formas mais híbridas, atravessadas por outras, num amálgama, ressaltando sobretudo seu caráter múltiplo e liminar/transfronteiriço. Outro pressuposto é o de que nossos territórios/territorialidades, ditos cada vez mais instáveis, móveis (algo que pode também ser contestado), não oferecem, como no passado, referenciais estáveis para a construção de nossas identidades sociais/territoriais. Neste caso, cabe a pergunta: acaso não é possível (como já indicamos anteriormente [Haesbaert, 2004]), também, territorializarmonos no e pelo movimento?

Iremos, então, problematizar a construção identitário-territorial contemporânea a partir das diversas formas de manifestação do chamado hibridismo cultural (especialmente aquele de matriz latino-americana, associado ao conceito de transculturação), alicerçado numa combinação desigual de forças, desde uma hibridização mais positiva, que propomos denominar de "antropofágica" (a partir de uma perspectiva brasileira), movimento assumido pelos grupos subalternos, a seu favor, até uma hibridização mais negativa, por ser imposta por ou beneficiar os interesses dos grupos hegemônicos.

Relacionada a esses múltiplos processos de hibridização focalizaremos sua contra-face territorial: a multi/transterritorialidade, também em suas diversas manifestações e intensidades. Essa diversidade de feições dos processos de hibridização e de (multi/trans) territorialização está inextricavelmente ligada, em primeiro lugar, às relações de poder que estão em jogo e, dentro destas, ao caráter cada vez mais mercantilizado, o crescente "valor de troca" incorporado aos nossos processos de identificação social/territorial ${ }^{4}$.

\footnotetext{
${ }^{4}$ Sobre a mercantilização das identidades, v. item "La identidad entre el valor simbólico y el valor de cambio: reconocimiento y mercantilización", em Haesbaert (2011, p. 52-55).
} 


\section{Hibridismo: ambivalência e antropofagia}

Ouve-se falar tanto de um processo de hibridismo cultural como marca maior da globalização contemporânea quanto, ao contrário, do domínio de uma "essencialização" identitária por parte de grupos fundamentalistas 5 . Por isso, ao trabalharmos, aqui, com os processos de hibridização como uma das características do nosso tempo (sem entrarmos na polêmica de se trata-se de uma dinâmica majoritária), temos que tomar muito cuidado. É preciso historicizar e geografizar melhor nossa concepção de hibridismo - ou de hibridização, para destacá-lo enquanto processo - e reconhecer, sobretudo, os diferentes sujeitos que o produzem e os contextos geopolíticos em que ele se realiza e/ou onde circula o seu debate - um pouco como nas "geometrias de poder" propostas por Massey (1994) para complexificar as relações em que se produzem a "compressão espaço-tempo" e as acessibilidades/velocidades do nosso tempo, cada vez mais múltiplas e diferenciadas.

É importante, assim, em primeiro lugar, situar o hibridismo dentro de suas raízes latino-americanas, a própria América Latina ${ }^{6}$ sendo vista, muitas vezes, como o "continente híbrido" por excelência - se não na prática, pelo menos amplamente no campo discursivo. Não é à-toa que temos alguns dos principais representantes desse debate especialmente na interface entre os estudos culturais e os estudos literários. Assim, por exemplo, o termo transculturação aparece inicialmente na década de 1940, em Cuba, no livro "Contraponto cubano del azúcar y del tabaco", de Fernando Ortiz. A noção tornou-se referência, sobretudo, na área da Antropologia, em torno das reflexões sobre o fenômeno da mestiçagem não apenas em Cuba, mas, por extensão, em toda a América. O ponto central da sua criação é a inexistência, segundo Ortiz, de um vocábulo que possa compreender o processo sempre em movimento e aberto de encontro

\footnotetext{
${ }^{5}$ Nessa perspectiva, a proposta mais conhecida e polêmica é a de Samuel Huntington (1996) e suas claras "fraturas" entre grandes civilizações como fonte prioritária de conflitos.

${ }^{6}$ Glissant (2005[1996]) prefere ser geograficamente mais preciso e distinguir uma "EuroAmérica", que inclui, além da quase totalidade da chamada América Anglo-Saxônica (Canadá e Estados Unidos, menos o sul), partes do "cone sul" chileno-argentino (ao qual deveríamos acrescentar Uruguai e sul do Brasil), e uma "Neo-América" ou "América da crioulização" (e do hibridismo), que "compreende o Caribe, o nordeste do Brasil, as Guianas e Curaçao, o sul dos Estados Unidos, a costa caribenha da Venezuela e da Colômbia, e uma grande parte da América Central e do México". (p. 16)
} 
entre diferentes sujeitos e suas culturas. Por isso, inspirado em Malinowski, Ortiz afirma que a palavra "transculturação":

(...) expressa melhor as fases do processo de transição de uma cultura a outra, já que este não consiste somente em adquirir uma cultura diferente, como a rigor sugere o vocábulo anglo-saxão, aculturação, mas implica também necessariamente a perda ou desenraizamento de uma cultura precedente, o que poderia ser chamado de uma parcial desculturação e, além disso, significa a consequente criação de novos fenômenos culturais que poderiam ser denominados neoculturação. (...) No conjunto, o processo é uma transculturação e este vocábulo compreende todas as fases da trajetória ${ }^{7}$. (ORTIZ, 1999:83, grifos do autor).

A noção de transculturação visava a superar a concepção limitada e "europeia" de aculturação e de mestiçagem racial, destacando o movimento contraditório que expressa o encontro de culturas e o processo de "criação de novos fenômenos culturais". É importante lembrar que, na mesma época, no Brasil, o antropólogo Gilberto Freyre, especialmente em seu livro "Casa Grande \& Senzala" (1933), produzia reflexões sobre o Brasil em torno das relações culturais (envolvendo a sexualidade) entre brancos e negras. Configuravam-se aí as raízes da chamada "democracia racial" brasileira (termo utilizado mais tarde por Freyre), especialmente a partir da região Nordeste, uma espécie de "berço da hibridização". De alguma forma podemos vincular esta interpretação ao pensamento de Fernando Ortiz.

O uruguaio Angel Rama, apropriando-se da noção de transculturação de Ortiz, desenvolveu a ideia de "transculturação narrativa" para os estudos literários. O ponto de partida, neste caso, é o debate entre vanguardismo (modernismo) e regionalismo. A partir da pressão modernizadora vinda do exterior, especialmente da Europa, as posturas

\footnotetext{
${ }^{7}$ No original: “... expresa mejor las diferentes fases del proceso transitivo de una cultura a otra, porque éste no consiste solamente en adquirir una distinta cultura, que es lo que en rigor indica la voz angloamericana aculturación, sino que el proceso implica también necesariamente la pérdida o desarraigo de una cultura precedente, lo que pudiera decirse una parcial desculturación, y, además, significa la conseiguiente creación de nuevos fenómenos culturales que pudieran denominarse de neoculturación. (...) En conjunto, el proceso es una transculturación, y este vocablo comprende todas las fases de su parábola".
} 
"regionalistas" podiam se configurar como: a aceitação das novas formas literárias oriundas de fora; a negação e rigidez cultural que não aceita a novidade estética; e a "plasticidade cultural", definida como uma produção literária "nova", mas que "integra" as novas estruturas formais sem recusar - incorporando - as próprias tradições. A essa "plasticidade cultural", Rama chama de literatura de transculturação. A noção de processo entre as culturas "modernas" e "regionalistas" é importante porque expressa uma perspectiva latino-americana da mescla de culturas, "inclusive no que pode ter de interpretação incorreta por considerar a parte passiva ou inferior do contato de culturas, a destinada às maiores perdas, sem nenhum tipo de resposta criativa" (RAMA, 2007:33).

Walter Mignolo (2003), em seu discurso pós-colonial, defendeu um "pensamento crítico de fronteira", ou uma episteme/"gnose liminar". Considera o autor que o conceito de transculturação foi um importante passo na construção de um pensamento das margens, embora Ortiz não tivesse demonstrado com clareza essas margens em relação à produção do conhecimento. Por isso, é importante pensar a noção de transculturação em termos de posições hegemônicas e subalternas, tanto no campo do conhecimento quanto da produção dos sujeitos ou grupos transculturados. Para Gosfrogel (2010), “o pensamento de fronteira não é um fundamentalismo antimoderno. E uma resposta transmoderna descolonial do subalterno perante a modernidade eurocêntrica" (p. 481, grifo nosso).

Sobre o pensamento transcultural ou híbrido latino-americano, além desses autores, podemos lembrar também Darcy Ribeiro que, em "O Povo Brasileiro" (1995), analisou a formação de um "brasilíndio mestiço", considerando que, do choque e da mistura do invasor português com índios e africanos escravizados teria resultado um povo novo, uma "nova etnia nacional" a partir de um gênero humano diferente, originado de uma "cultura sincrética" e singularizada ${ }^{8}$.

8. Munanga (2010), embora trabalhe com a ideia de "transculturação" da sociedade brasileira, questiona esse caráter sincrético e prefere qualificá-la como "cultura plural" ou de pluralidades, feita de "colcha de retalhos e não de síntese" e que, por isso, não impede a formação e manifestação de minorias étnicas. Nesta e em outras obras o autor defende que nosso "modelo sincrético" não é democrático, mas "assimilacionista", construído pela pressão de uma elite dirigente em moldes eurocêntricos, marcado pelo "branqueamento" e a inibição da manifestação das identidades étnicas frente a essa "identidade nacional" de mestiçagem (quando o próprio mestiço, por sua expressão numérica, constitui "a categoria social mais excluída e discriminada" [2010:451]) 
Por fim, Édouard Glissant (2005[1996]), a partir do olhar caribenho, defendeu a "crioulização" americana (e mesmo mundial), e Nestor Canclini (1998[1989]), num olhar mais amplo, focalizou nossas "culturas híbridas", afirmando que hoje "todas as culturas são de fronteira", "todas as artes se desenvolvem em relação com outras artes", sendo que as culturas e os sujeitos perderam a relação "exclusiva" com seu território, mas ganharam em comunicação, inter-relação, conhecimento e, por extensão, em potencial de hibridização.

Sobre o hibridismo, Young (2005) assim se reporta:

O hibridismo transforma (...) a diferença em igualdade, e a igualdade em diferença, mas de forma tal que a igualdade não seja mais o mesmo, e o diferente não mais simplesmente o diferente. (...) quebrar e reunir ao mesmo tempo e no mesmo lugar: diferença e igualdade numa aparentemente impossível simultaneidade. (p. 32)

A ambivalência é, assim, uma marca inerente aos processos de hibridização. Mas é o próprio Young quem, apesar de propor uma leitura mais pós-estruturalista, "dialógica", do que propriamente dialética da questão, refere-se ao hibridismo tanto como uma "fusão" quanto como uma "articulação dialética". Este "hibridismo duplo", diz ele, comentando Salman Rushdie, "foi considerado um modelo que pode ser utilizado para as formas de sincretismo que caracterizam todas as culturas e literaturas pós-coloniais" (p. 29). Pode-se afirmar que o hibridismo opera simultaneamente de maneira dupla, "'organicamente', hegemonizando, criando novos espaços, estruturas, cenas e, 'intencionalmente', diasporizando, intervindo como uma forma de subversão, tradução, transformação" (Young, 2005:30).

Para Stam, por sua vez, numa preocupação eminentemente política, o discurso dominante sobre o hibridismo:

... falha em termos de discriminar entre as diversas modalidades de hibridismo, tais como imposição colonial (...) ou outras interações como assimilação obrigatória, cooptação política, mimetismo cultural, exploração econômica, apropriação de cima para baixo, subversão de baixo para cima. (Stam, 1999:60; destaque nosso)

Para exemplificar, o hibridismo das identidades sociais num contexto (pós)colonial culturalmente tão rico e nuançado como o latino- 
americano, não é apenas um instrumento de ruptura com a "unidade" cultural do colonizador, desterritorializando tanto grupos hegemônicos (num nível mais atenuado) quanto subalternos (num nível muito mais violento), mas representa também uma forma de resistência/reterritorialização às vezes bastante rica, recriando, pela mistura, novas formas de construção identitário-territorial.

Algumas sociedades e espaços vivem o hibridismo de maneira mais pronunciada, ou são forçadas e/ou encontram-se mais abertas a trocas culturais muito mais intensas. O historiador cultural Peter Burke, em um trabalho sobre o hibridismo (Burke, 2003), afirma que este, quando imposto, pode representar importantes perdas culturais. Mas, como deve ser considerada sempre uma via de mão dupla, a hibridização também pode se transformar num instrumento de inovação e/ou de resistência, como foi muito claramente defendido na visão "antropofágica" do escritor modernista brasileiro Oswald de Andrade.

Pretendemos, por isso, deter-nos um pouco na interpretação daquilo que propomos denominar "hibridismo antropofágico", , a faceta de um hibridismo de contextualização brasileiro-latino-americana dotada de um sentido claramente positivo e que foi pautada de forma pioneira na ousada leitura literário-filosófica de Oswald de Andrade.

A antropofagia oswaldiana surgiu sob o signo do paradoxo, pois representou uma abertura à experiência do novo através da releitura do arcaico. Jáuregui (2005) afirma que essa antropofagia "transforma e usa o tropo do canibalismo como metáfora de choque vanguardista com a tradição, o Romantismo indianista, as instituições acadêmicas, o conservadorismo católico e o nacionalismo xenófobo" (p. 579), identificada mesmo com a noção de "brasilidade". Inserindo uma dimensão inédita ao estudo das estratégias culturais presentes no Brasil, Gomes (2005:51), por sua vez, considera que "a noção metaforizada de canibalismo, acrescida e enriquecida pela contribuição, eminentemente brasileira, da Antropofagia oswaldiana", compreende "uma forma fecunda de crítica cultural e acrescenta novos dados e indagações à questão da alteridade" e, portanto, do próprio hibridismo.

\footnotetext{
${ }^{9}$ Um exercício interessante, que limitações de tempo não nos permitem realizar aqui, seria discutir esta visão "antropofágica" à luz da noção de "hibridismo selvagem" de Homi Bhabha (1998), retomada como "hibridismo cultural” por Alberto Moreiras (2001).
} 
Para Oswald, em seu "Manifesto Antropofágico", "só a antropofagia nos une", tanto social quanto econômica e filosoficamente (Andrade, 1995:47). Ao contrário da visão dos colonizadores, com sua "interpretação materialista e imoral" da antropofagia, esta é, para ele, uma visão de mundo, uma Weltanschauung advinda de certa "fase primitiva" da humanidade e seu rico mundo espiritual:

Contrapõe-se, em seu sentido harmônico e comunial, ao canibalismo que vem a ser a antropofagia por gula e também a antropofagia por fome, conhecida através da crônica das cidades sitiadas e dos viajantes perdidos. A operação metafísica que se liga ao rito antropofágico é a da transformação do tabu em totem. Do valor oposto ao valor favorável. A vida é devoração pura. Nesse devorar que ameaça a cada minuto a existência humana, cabe ao homem totemizar o tabu. Que é o tabu senão o intocável, o limite? (1995:101)

Romper a "cultura messiânica" do colonizador com a cultura liminar, "antropofágica", dita "selvagem" dos povos originários é, em termos muito gerais, a proposição de Oswald de Andrade. Nada de fins preconcebidos, teleologia rumo à redenção divina, mas o refazer constante do Outro - e de si mesmo - pela "devoração pura". Uma outra espécie de "destruição criadora" daqueles que se alimentam constantemente deglutindo a própria força do Outro.

Em outras palavras, o hibridismo como força, a antropofagia como arma: devorar é instigar a re-criação constante, o brotar de um pensamento mítico-poético indomável pelo utilitarismo e a domesticação do pensamento e das identidades euro-colonizadoras. Como afirmou Maltz (1993):

Destruir para construir em cima. Deglutir para, de posse do instrumental do "inimigo", poder combatê-lo e superá-lo. Deglutir o velho saber, transformando-o em matéria-prima do novo. (...) a contrapartida dessa atitude de inércia ideológica e cultural, de brutal assimilação que legitimava a influência estrangeira, seria a atitude antropofágica de "deglutir" o saber europeu, "devorando-o" não mais para incorporá-lo de modo mecânico mas para absorvê-lo dialeticamente na tentativa de abrasileirar a nossa cultura, dando-lhe uma identidade [no hibridismo, poderíamos 
acrescentar]. (...) dessacralizar a herança cultural do colonizador para inaugurar uma nova tradição. (1993:11)

Por isso alguns autores, como Helena (1983), definem a antropofagia como "ethos da cultura brasileira" (p. 91). A antropofagia constitui assim a face de "positividade" do hibridismo - que, se por um lado pode representar destruição e empobrecimento de culturas pretéritas, por outro pode rejuvenescê-las e impeli-las para o novo, que também pode ser mais rico. "Totemizando o tabu", a sociedade antropofágica viola o intocável, rompe com os limites (ou vive pelos/nos limites...), des-reterritorializa-se num espaço onde a multiplicidade não é simplesmente um estorvo ou um resquício, é uma condição de existência e de recriação não-estabilizadora do novo.

A filosofia antropofágica sem dúvida antecipou o pensamento póscolonial, preocupado antes de tudo com a contextualização das epistemes pela natureza geo-histórica de sua produção (a este respeito ver, especialmente, Mignolo, 2003, já citado). Esta leitura cultural dos processos de hibridização/antropofagização pode instigar-nos a pensar, também, a um nível mais concreto, como reconhecer, ou melhor, politicamente falando, como articular e instigar a criação de espaços capazes de reproduzir e/ou de induzir a esta condição subversora. Propomos então retrabalhar o nosso conceito de "multi" ou "transterritorialidade" (Haesbaert, 1996, 2001, 2004, 2007) à luz dos processos de hibridização na perspectiva da transculturação e da antropofagia.

\section{Hibridismo e multiterritorialidade}

O espaço, como sabemos, mais do que referente intelectual ("absoluto") para nossa localização no mundo ou do que simples coexistência de objetos materiais em relação no nosso entorno, é constitutivo de nossa própria existência, tanto na sua dimensão físicobiológica (enquanto "corpo" - que para alguns seria nosso "primeiro território"), quanto na sua dimensão simbólico-social. Deste modo, se falamos que o homem é não somente um "homem espacial" (Lussault, 2007) mas ainda um "homem multiterritorial", experienciando ao mesmo tempo diversos territórios - espaços sob algum tipo de controle -, isto significa que essa dimensão espacial não é mera referência, palco ou 
apêndice da condição humana, mas uma de suas dimensões constitutivas fundamentais.

Para analisarmos, desse modo, a relação entre hibridismo e multiterritorialidade precisamos, em primeiro lugar, retomar, ainda que rapidamente, o que entendemos por território e por territorialidade. Já na sua origem a noção de território nasce com um duplo significado, material e simbólico, envolvendo as relações sociais, sobretudo na dimensão do poder, desde o sentido de terra-territorium, relativo à dominação (jurídicopolítica) da terra - propriedade privada, no caso do capitalismo -, até a perspectiva de terreo-territor (terror, aterrorizar) com a inspiração do terror, do medo - especialmente para aqueles que, com esta dominação, ficam alijados da terra, ou no "territorium" são impedidos de entrar ${ }^{10}$.

Partindo de um conceito menos parcelar de território, não definindo conceitos simplesmente por um recorte empírico, uma "parcela do real", mas por uma problemática e uma forma de abordá-la, ou seja, por um determinado "olhar" e, nele, um "foco" sobre a realidade, defendemos que o território é o espaço geográfico visto a partir de um foco nas relações de poder, seja o poder em seus efeitos mais estritamente materiais, de âmbito político-econômico (da "soberania" e da "disciplinarização", numa linguagem foucaultiana), seja em sua articulação cultural, mais simbólica. Assim, trata-se de abordar o território através das relações de poder que lhe são inerentes - desde um poder mais "tradicional", de natureza estataladministrativa, até sua configuração mais simbólica, onde a própria construção identitária é vista, sobretudo, como um instrumento de poder (ou, para utilizar um termo em voga, de "empoderamento") dos grupos e/ou classes sociais ${ }^{11}$.

Territorialidade, por sua vez, não será tratada, de forma culturalista e mais restrita, como a simples dimensão simbólica do território, nem como, de forma mais ampla e abstrata, como a genérica "condição" ou "qualidade" de existência do território. Propomos tratar aqui a territorialidade como a "multidimensionalidade do vivido territorial" (Raffestin, 1993 [1980]) ${ }^{12}$, expressa por meio de um conjunto de relações

10 Para um debate mais aprofundado da relação entre território e territorialidade ver, especialmente, Haesbaert (2004 e 2007).

11 Reportamo-nos aqui, também, à concepção de poder simbólico de Pierre Bourdieu (1989).

12 Essa concepção envolve, mas vai além, (d)aquela proposta por Sack (1986), de caráter mais materialista, que vê a territorialidade como uma estratégia (concreta) de controle da 
(de poder, acrescentaríamos), funcionais e/ou simbólicas, entre sociedade e espaço. Nesse sentido, embora a eles não redutível, ela se encontra imersa num universo de valores simbólico-identitários que não obrigatoriamente implica na construção efetiva, concreta, de um território - ou seja, ainda que todo território implique uma territorialidade, pode existir territorialidade sem que ocorra a construção efetiva do território (Haesbaert, 2007).

Nessa perspectiva, a territorialidade também pode ser construída, funcional e/ou simbolicamente, pela combinação de um conjunto de lugares (ou de outros territórios), pela produção de um circuito (como nos percursos nômades), pela constância do movimento, já que está cada vez mais presente a possibilidade de acessar, ingressar, sair e transitar entre distintos territórios.

Haveria, assim, a configuração de (multi)territorialidades de maior carga funcional e outras de maior carga simbólica, de acordo com a força das funções e dos significados que lhe são atribuídos pelos diferentes sujeitos sociais em (territorializ)ação. $\mathrm{Na}$ abordagem aqui priorizada, interessa-nos mais os territórios dotados de forte significação/simbolização, passíveis de estarem envolvidos numa hibridização em termos culturais. Não podemos ignorar, aí, a forte relação entre formas políticas de gestão territorial e as implicações em termos da propensão que carregam para a realização de formas culturais mais (ou menos) híbridas de identificação social.

Produzir culturas híbridas, portanto, como referido por Canclini (1997[1989]), significa construir espaços de alguma forma também híbridos, liminares ou (trans)fronteiriços (como na Tijuana da fronteira México-Estados Unidos, por ele abordada), territórios múltiplos cujo desenho interfere diretamente nas nossas concepções de mundo, na construção de nossas identidades sociais. A própria multiterritorialidade contemporânea pode, portanto, favorecer processos de territorialização por hibridização, seja através de nossa crescente mobilidade física, articulando mais de um território, como ocorre com os migrantes em diáspora, seja pela própria diversidade territorial in situ, como ocorre especialmente em certos espaços mais cosmopolitas das grandes cidades globais. Nestas, em espaços relativamente restritos, às vezes um mesmo bairro, pode interagir um número culturalmente muito diversificado de pessoas e grupos.

acessibilidade pelo controle de fluxos - seja de pessoas, ideias, informações e/ou mercadorias - em determinada área. 
A multiterritorialidade, podemos dizer, manifesta-se de duas formas gerais: uma, de caráter mais amplo, que pode ser denominada de "multiterritorialidade lato sensu" ou sucessiva, e que envolve a vinculação de múltiplos territórios (zonais) articulados em rede, implicando, para os grupos sociais, um determinado grau de mobilidade física; e outra, de caráter mais específico, que podemos denominar "multiterritorialidade stricto sensu" ou simultânea, e que envolve territórios em si mesmos híbridos e/ou que permitem a articulação simultânea com outros territórios (por mecanismos de controle informacional).

No primeiro caso, nossa hibridização é, digamos, induzida pela mobilidade. É imprescindível que vivenciemos o deslocamento físico para que tenhamos nossa experiência - e nosso "controle" - multiterritorial. Com a importante ressalva de que, obviamente, nem todos os que se movem por diferentes espaços vivenciam, obrigatoriamente, de fato, uma multiterritorialidade - para além de seu caráter meramente funcional.

Não é simplesmente por termos maior mobilidade ou por habitarmos territórios (ou lugares, na ampla abordagem de lugar da geografia anglosaxônica) cada vez mais híbridos que, automaticamente, estaremos vivenciando um maior hibridismo cultural e identitário. A burguesia planetária, por exemplo, desloca-se muito, mas quase sempre frequentando os mesmos lugares, ignorando a imensa diversidade cultural - e territorial - que se estende ao seu redor. Aqui e ali ela pode até cruzar com o Outro, mas é como se ele estivesse invisibilizado, não se estabelecendo nenhum diálogo - ou, quando, por obrigação, este se dá (como em serviços de hotéis/restaurantes, meios de transporte ou no comércio), trata-se de um contato de caráter meramente funcional.

Por outro lado, não é também por habitarmos espaços reveladores de uma grande diversidade étnica que, automaticamente, estaremos vivenciando uma multiterritorialidade no seu sentido simbólico-cultural. Há aqui a importante distinção entre seu caráter potencial e efetivo. Podemos viver numa cidade altamente cosmopolita e culturalmente múltipla, como Londres ou Nova York e, no entanto, negarmo-nos a usufruir dessa multiplicidade. Neste sentido, podemos partilhar "múltiplos [tipos de] territórios" - ou uma multiterritorialidade - meramente funcional, sem construir ali, efetivamente, uma multiterritorialidade em seu sentido simbólico. Esta, implicando o transitar e, mais ainda, o vivenciar dessa multiplicidade de territórios/territorialidades cria, com isso, vínculos simbólico-afetivos e não somente físico-funcionais com os territórios. 
Isso significa que as relações entre hibridismo cultural e multiterritorialidade não são biunívocas: podemos ter, por exemplo, uma multiterritorialidade funcionalmente articulada sem que se promovam ali experiências de hibridização cultural. É interessante ressaltar, entretanto, que a maior mobilidade do nosso tempo, tanto na perspectiva de uma multiterritorialidade sucessiva (que implica deslocamento físico) quanto simultânea ("in situ", através de um local culturalmente múltiplo, ou "informacional-virtual" - quando permite aceder e/ou "controlar" territórios à distância), é um elemento potencialmente favorecedor - e muito - dos processos de hibridização.

Como já havíamos indicado inicialmente, não podemos esquecer que uma forma de territorialização também é aquela que se realiza "no e pelo movimento". Inúmeros são aqueles que, hoje, identificam-se com essa mobilidade - de tal forma que, para eles, o território, e as identidades aí incorporadas, é construído na multiplicidade, pelo amálgama de múltiplas territorialidades ou - de maneira mais estrita, pelo próprio "estar em movimento" ou transitar entre múltiplos territórios, o que nos leva, também, a pensar numa forma quase constante de trânsito entre territórios ou, em outras palavras, numa "transterritorialidade".

\section{Hibridismo em aberto: da transculturação à transterritorialidade}

Em uma escala mais pessoal ("subjetiva"), posso ser amigo de um bengali muçulmano na Biblioteca Britânica, um contato que se resume àquela instituição e seu caráter funcional, numa relação muito mais entre funcionário e usuário - outra coisa, muito diferente, é desdobrar laços afetivos com sua família pela frequência constante a seu bairro no leste de Londres. Aqui, pelo transitar efetivo por múltiplos territórios/territorialidades, ainda que em nível pessoal, posso afirmar que estou produzindo uma multiterritorialidade - ou, num termo provavelmente mais adequado, uma transterritorialidade, pois ela implica, mais do que a articulação de territórios distintos, o trânsito e a vivência entre eles, em sua imbricação, resultante de uma frequente mobilidade entre o bairro de predomínio bengali e "meu" bairro tipicamente inglês do sudoeste de Londres ${ }^{13}$.

${ }^{13}$ É justamente em relação aos migrantes em diáspora que se formula o conceito políticocultural de "transnacionalismo", "representando fenômenos contemporâneos relacionados 
Assim como o hibridismo não corresponde a uma condição estanque, propriamente um "estado", mas um processo em incessante ir-e-vir - ou, em outras palavras, em constante devir -, a multi ou transterritorialidade também deve ser vista, sobretudo, dentro de um movimento de entrada, saída e, mais do que isto, de trânsito entre diferentes territórios. O que mais importa aqui é a condição de possibilidade, sempre em aberto, de nossa inserção em "território alheio" (que também passa, assim, de forma ambivalente, a ser "nosso"), a abertura desses territórios que coloca permanentemente a possibilidade de entrar, sair e/ou transitar por essas territorialidades.

É por enfatizar essa ideia de movimento, de abertura e de trânsito que talvez o termo mais apropriado seja construído não pelo prefixo "multi", mas pelo prefixo "trans", como já sugeríamos há mais de uma década (Haesbaert, 1996, em citação que abre este texto), e como propõem outros autores ${ }^{14}$. Já que estamos enfatizando essa dimensão cultural da territorialização, é importante determo-nos um pouco mais, agora, nos vínculos com os processos de transculturação.

Para o antropólogo cubano Fernando Ortiz (1983:90), "as diferentes fases do processo de transição de uma cultura para outra" passam por três momentos: aculturação, desculturação e neoculturação. $\mathrm{O}$ primeiro momento constitui-se pela aquisição de outra cultura, ele é a soma; o segundo momento corresponde ao "desenraizamento de uma cultura anterior", é a perda; e, o terceiro, à "criação de novos fenômenos culturais" que, numa visão de conjunto e de processo, produzem a transculturação trata-se do amálgama entre ganhos e perdas, poderíamos acrescentar. A transculturação opera, assim, pelo atrito das culturas que expressa uma

com a migração em massa e os processos de mudança política e cultural através dos espaços nacionais" (McEwan, 2008:499).

${ }^{14}$ É interessante destacar que "transterritorialidade" não obrigatoriamente dá ênfase ou mesmo se refere à dimensão cultural, como aqui enfatizamos. Em Haesbaert (2004), por exemplo, comentávamos a perspectiva econômica de Giovanni Arrighi (1996), para quem "as multinacionais admitem o princípio da "transterritorialidade" - neste caso, a concepção de território do autor se complexifica, e "as 'organizações empresariais não territoriais' globais [p. 84] passam a se organizar em 'múltiplos territórios' (a 'multiterritorialidade' [...]) ou, numa concepção mais polêmica, 'transterritorialmente"" (Haesbaert, 2004:182). Trata-se, poderíamos dizer, de uma "transterritorialidade funcional", ou seja, de uma "multiterritorialidade" em seu sentido funcional, para a distinguirmos da noção de transterritorialidade aqui trabalhada. 
perspectiva criadora através de perdas, conflitos, assimilações, negociações e cruzamentos.

Por isso, na relação e intercâmbio de elementos que pode ser feita entre transculturação e transterritorialização, entendemos que merece destaque a dimensão do trânsito e/ou de transição identitária desencadeada pelas transformações culturais imersas na maior fluidez, componente indissociável (ainda que profundamente desigual) da espacialidade contemporânea. A esse respeito, podemos pensar, numa aproximação com Fernando Ortiz, que o trânsito na produção de territorialidades corresponde à dimensão espacial dos processos de transculturação. Desenha-se assim o caminho, o itinerário, o circuito da mobilidade (mais ou menos facilitada conforme a territorialidade) envolvido em processos de transculturação.

Enquanto a multiterritorialidade pode implicar a passagem de um território (ou territorialidade) para outro, assumindo-se novas condições em momentos diferentes de um mesmo processo - ainda que temporalmente próximos entre si - , a transterritorialidade é a manifestação de uma multiterritorialidade em que a ênfase se dá no estar-entre, no efetivamente híbrido, produzido através dessas distintas territorialidades. É claro que, diferentemente da distinção analítica aqui realizada, na prática a fronteira entre essas situações é extremamente maleável e fluida - tanto podemos "adotar" uma territorialidade diferenciada para logo depois abandoná-la, quanto incorporá-la na reconstrução dos referentes territoriais que passarão a nos acompanhar de forma indissociável.

Transterritorialidade, assim, envolve não apenas o trânsito ou a passagem de um território ou territorialidade a outra, mas a transformação efetiva dessa alternância em uma situação nova, muito mais híbrida. Destaca-se a própria transição, não no sentido de algo temporário, efêmero e/ou de menor relevância, mas no sentido de "trânsito", movimento e do próprio "atravessamento" e imbricação territorial - não um simples passarpor mas um estar-entre.

Essa transição de territórios/territorialidades se manifesta como uma relação de "fronteira", nos entrecruzamentos e nas sobreposições de relações sócio-espaciais. É possível fazer aqui, claramente, a analogia - e até uma tentativa de transposição de elementos - entre a definição de transculturação de Ortiz e a de transterritorialização. Enquanto a primeira é vista como produto do jogo entre desculturação e neoculturação, os processos geográficos de transterritorialização resultariam da imbricação entre desterritorialização e re(ou "neo", para sermos fiéis a 
Ortiz)territorialização - a transterritorialização não simplesmente como o conjunto desse processo (como indicaria Ortiz), mas como uma modalidade de reterritorialização. Moreiras (2001), embora partindo do conceito de hibridismo, afirma, nesse mesmo sentido:

O conceito de hibridismo é complexo e particularmente sugestivo porque pode ser usado para agrupar fenômenos que derivam tanto da territorialização quanto da desterritorialização. No caso da última, o hibridismo se refere aos processos de perda em posições previamente determinadas (isto é, o hibridismo aumentaria no mundo de hoje porque há desculturação, e a desculturação é uma perda bruta, irremediável). No caso da primeira, o hibridismo se refere à positividade que tal perda implica, estruturalmente ou constitutivamente (não há desculturação sem reculturação), e a reculturação pode até produzir - sob certas circunstâncias - uma ameaça à própria economia do sistema). A reterritorialização híbrida e a desterritorialização híbrida são então dois lados - diferentes - da mesma moeda. (p. $342)^{15}$

Angel Rama, como já destacamos, no campo dos estudos literários, a partir dos anos 1970, também desdobrou o conceito de transculturação, embora enfatizando outra escala, a intranacional. Enquanto Ortiz focalizou a formação transcultural de uma sociedade nacional, a cubana, em relação ao contexto do colonizador, a Europa, Rama destaca também as relações intranacionais - entre "centro" ("capital ou porto", "vanguardista", voltado para fora) e "periferia" (ou "cultura regional interna", de tendências mais rurais, voltada para dentro) ${ }^{16}$.

${ }^{15}$ Embora Moreiras destaque mais a ideia de uma "desterritorialização" má e uma boa "reterritorialização", obviamente isto nem sempre ocorre desta forma. Sobre a crítica da associação às vezes unilateral entre hibridismo e desterritorialização, ver, além de Moreiras (2001), Kraniauskas (1992), Tomlinson (1999) e o nosso próprio trabalho (Haesbaert, 2004, especialmente o item "A desterritorialização numa perspectiva cultural", p. 214-234)

${ }^{16}$ Para uma análise dessa perspectiva de Rama no campo literário e suas perspectivas contemporâneas, v. Aguiar e Vasconcelos (2004). Embora os autores a ela não se refiram, podemos associar, numa abordagem mais política, a "transculturação" de Rama com a noção de "colonialismo interno" desenvolvida por González-Casanova (1965). 
Três funções fundamentais ocorrem no interior das narrativas consideradas por Rama (2007) como transculturadas: o uso da língua, a estruturação literária e a cosmovisão. Esses três momentos da transculturação narrativa são produzidos pelo contato cultural provocado pela modernização, oriunda da capital, das formações urbanas cosmopolitas colocadas em contato com as culturas regionalistas, das cidades menores, vinculadas mais às características rurais. Desse modo, os processos de narração transculturada foram resultado de séculos de colonização, pelo contato e negociação cultural que promoveu a crioulização ou "assimilação" dos códigos culturais europeus por meio da hibridização. Sua visão de cultura, portanto, é funcional e, ao mesmo tempo, dinâmica, pois "utensílios, normas, objetos, crenças e costumes, somente existem em articulação viva e dinâmica, que é a que desenha a estrutura funcional de uma cultura" (Rama, 2007:39). Assim, ao mesmo tempo em que compreendia a transculturação narrativa pela "plasticidade cultural", desenvolvia sua análise através de escalas variadas entre modernização (centro) e regionalismo (periferia) ou, se quisermos, de modo mais amplo, entre regional, nacional e global.

Abre-se, portanto, um outro "jogo" espacial - muitas vezes, também, territorial - a que podemos denominar "jogo de escalas" (parafraseando o título do livro de Revel [1998]), e através do qual igualmente se desenham processos como os aqui denominados de multi e/ou transterritorialização. Não se trata de um simples trânsito, "acúmulo" ou "passagem" de uma escala a outra, mas a vivência concomitante de múltiplos territórios, articulados e sobrepostos em termos que lembram, um pouco, o que Yves Lacoste (1988) denominou de "espacialidade diferencial". "Diferencial" aqui implicando, é claro, não simplesmente uma "diferença de nível" ou "de grau", quantitativa e hierárquica (de uma escala cartograficamente maior e menos importante para uma menor e mais importante, por exemplo), mas a efetiva diferenciação qualitativa ("diferença de natureza") a partir do novo amálgama, multifacetado, aí construído ${ }^{17}$.

\footnotetext{
${ }^{17}$ Algumas multiterritorialidades, nesse sentido, não representam senão uma diferença de grau, como na organização multiterritorial dos Estados-nações, estruturados de modo a "encaixar" múltiplas escalas dentro de uma mesma ordem político-territorial, que se estende, por exemplo, do território do município (ou condado) ao Estado (ou província), daí ao Estado-nação e, hoje, a blocos político-econômicos, especialmente no caso da União Europeia.
} 
$\mathrm{Na}$ relação entre hibridismo ou transculturação e multi ou transterritorialidade devemos ter sempre o cuidado para não reduzi-la a uma relação de causa e efeito. Não se deve ver o espaço/o território como simples reflexo desses processos de hibridização, muito menos a mudança territorial como um determinante da transculturação - o espaço e o território são elementos constitutivos fundamentais e indissociáveis dessa mesma dinâmica. Nesse sentido, espaços transfronteiriços, por exemplo, podem ser considerados emblemáticos, já que são muito mais suscetíveis a processos de hibridização - tanto por uma dinâmica, digamos, mais "espontânea", quanto por "obrigação" ou "necessidade", já que transitar e/ou mesclar identidades (nacionais, por exemplo), compreende ali, também, uma estratégia ${ }^{18}$ de sobrevivência.

Mondardo (2009) desenvolveu uma proposta de transterritorialidade, sobretudo para compreender a migração, a partir de um processo que vê o migrante como ser em trânsito, seja como força de trabalho, seja em outras formas de mobilidade. Estabelece-se aí uma relação tensa e ambivalente na condição de pertencimento e vivência com/no novo território. $\mathrm{O}$ migrante cria vínculos afetivos e/ou materiais com o território de origem, numa situação ambígua, "de ser de dois (ou mais) territórios e não ser de nenhum", caracterizada por uma espécie de "translocamento" (p. 105) ${ }^{19}$. É nesse trânsito entre os territórios de origem e de destino que o migrante produz uma condição de transterritorialidade, num "processo de imbricação (conflituoso) do sentimento de pertencer, das relações 'carregadas' consigo (na memória) dos outros territórios perpassados (...), além dos estranhamentos, das relações dúbias, ambivalentes", que provocam "o embaralhamento das referências espaciais", fazendo o sujeito pertencer a (e até "viver", de alguma forma, pela memória, por exemplo) duas territorialidades, e ao mesmo tempo, não pertencer a nenhuma.

Nessa transterritorialidade migratória, o autor considera que, "como a vida do migrante se dá em fronteira, como espaço cultural híbrido, podemos percebê-lo como movimento processual de transterritorialidade", ocorrendo "pelo e no entrecruzamento cultural e político (em sentido amplo) entre múltiplas identidades, territorialidades e temporalidades" (2009:104). Por isso, essa manifestação de transterritorialidade na

\footnotetext{
18 Para Moreiras (2001) tratar-se-ia mais de uma tática do que de uma estratégia. Sobre este debate, envolvendo a noção de "essencialismo estratégico" de Gayatri Spivak, ver especialmente p. 336-337.

19 A propósito, ver a noção de "translocalidade" de Appadurai (1997).
} 
migração é "uma relação que transcende o lugar de origem e de destino, pois é uma condição ambígua e tensa de sentimentos, de desejos, de representações", ausência e presença que processa a transterritorialização e, portanto, que gera a condição paradoxal de que fala Sayad (1998), de ser, concomitantemente, e/imigrante. Assim, numa perspectiva mais subjetiva da migração, a transterritorialidade "pretende compreender a ligação e a tensão com o lugar-presente do migrante e com o seu inverso: o lugar-ausente do migrante" (2009:108). Nessa relação dúbia, "transterritorial", o migrante é colocado "na fronteira entre lugares", sempre ao mesmo tempo "aquele que foi" e aquele "que permanece", entre o espaço que perdeu, que não mais lhe pertence e aquele a que de alguma forma deveria pertencer, mas que ainda lhe é estranho ${ }^{20}$.

Goettert e Mondardo (2009), por sua vez, desenvolvem uma ideia de transterritorialidade num diálogo com a noção de multiterritorialidade de Haesbaert (2004), para entender o "Brasil migrante" ou os processos de mobilidade da força de trabalho pelo território brasileiro, focalizando as relações de poder na construção das territorialidades que são colocadas em tensão, em choque, em diálogo e entrecruzamentos. A partir desse processo conflituoso, as territorialidades em contato possibilitam a produção de transterritorialidades em modalidades "abertas" e "fechadas", pois "marcadas por relações de poder, as transterritorialidades, quando negadoras da territorialidade do Outro, manifestam-se como "fechadas"" e "quando passíveis de incorporação pelo menos parcial da territorialidade "estranha', do Outro, apresentam-se como 'abertas"” (121). Essa distinção destaca a produção múltipla de transterritorialidades através da desigualdade das relações de contato e/ou de choque entre identidades territoriais que apontam uma maior ou menor abertura para o Outro.

$\mathrm{Na}$ verdade, tornando mais precisa a rica ideia do complexo jogo de poder e do aspecto conflitivo na construção de transterritorialidades, não se trata de "negação da territorialidade do Outro", pois deste modo, tomada esta negação de maneira estrita, seria muito difícil ocorrer a transterritorialidade (a não ser num sentido meramente funcional), e sim, muito mais, a imposição de uma territorialidade hegemônica sobre a outra, subalterna. Ao invés de "negação", propomos falar de uma transculturação ou "integração" imposta, compulsória e unilateralmente dirigida, em que os elementos da territorialidade alheia a serem incorporados/transformados o

20 Daí surgem, em nível transnacional, concepções como a de "transmigração" ou de "transmigrante" (Schiller et al., 1995). 
são por uma seletividade direcionada, sobretudo, pelos grupos hegemônicos. Isso parece ter ocorrido de forma mais drástica nas relações entre as culturas africanas e a dos colonizadores portugueses no Brasil. É claro que nunca se trata de um processo de mão única mas, em casos como esse, de amplo predomínio ou imposição dos anseios de um grupo sobre o outro.

Uma transterritorialidade imposta se dá, portanto, de maneira forçada, tanto pelas condições estabelecidas, de forma mais direta, por um grupo hegemônico quanto, mais indiretamente, pela condição de precarização a que grupos subalternos podem estar relegados. Esse seria o caso da força de trabalho migrante que precisa se "adaptar" a novos e muito diversos territórios a cada nova mudança.

A importante valorização do caráter conflitivo da transterritorialidade permite-nos falar, em outras palavras, numa transterritorialidade moldada pela imposição transcultural e outra, mais "aberta", por um diálogo mais igualitário, de trocas positivamente acionadas, um pouco como na "antropofagia" oswaldiana, capitaneada pelos "de baixo" e/ou pelos "locais" (nunca, assim, estritamente "locais").

\section{Hibridismo e (trans)territorialização: implicações políticas}

A abertura e a mobilidade territorial, que alguns, equivocadamente, associam estritamente a processos de desterritorialização, têm grande relevância no estímulo às trocas culturais, aos processos de hibridização e/ou transculturação. Se estes movimentos são político-socialmente positivos ou negativos, contudo, é uma outra questão - mas uma questão nada desprezível. Para além do debate em torno de seu valor heurístico, conceitual, hibridismo e multi ou transterritorialidade passaram, muitas vezes, a uma espécie de programa político. Como afirmou Nestor García Canclini:

Uma política é democrática tanto por construir espaços para o reconhecimento e o desenvolvimento coletivos quanto por suscitar as condições reflexivas, críticas, sensíveis para que seja pensado o que põe obstáculos a esse reconhecimento. Talvez o tema central das políticas culturais seja, hoje, como construir sociedades como projetos democráticos compartilhados por todos sem que igualem todos, em que a desagregação se eleve a diversidade, e as desigualdades (entre 
classes, etnias ou grupos) se reduzam a diferenças. (Canclini, 1998:157)

Qual, então, o tipo de hibridismo (ou, se preferirmos, de transculturação) que desejamos promover? Qual o tipo de multi/transterritorialidade que permite estimular estes processos "positivos" (ou, em outros termos, como aqui foi colocado, "antropofágicos") de hibridização?

Não podemos esquecer, retomando considerações iniciais, que também o (discurso do) hibridismo está na moda - e, assim, como tudo que está na moda, tem alto "valor de troca". Como afirmou Moreiras (2001):

... o hibridismo pode atualmente quase ser, em seu aspecto performático [não constatativo], uma espécie de disfarce ideológico para a reterritorialização capitalista. (...) Argumentar em favor do hibridismo, contra a reificação das identidades culturais, como uma espécie de prescrição para a flexibilidade perpétua, é exagerar sua utilidade. (p. 316)

É "bom" ser híbrido, "mestiço", créole, também porque isso "vende" - e vende porque nos dizem que faz bem realizar misturas, desenraizar-se, circular constantemente por territorialidades diferentes, enfim, consumir o world hybrid - talvez uma nomenclatura que pode sintetizar esta vertente mais comercial e globalizada do hibridismo. Só somos efetivamente "globais" se formos "híbridos". Aqui aparece outro elemento fundamental neste debate, e para o qual poucos parecem atentar: dependendo da escala em que é abordado, o hibridismo adquire feições e implicações políticas distintas. Descontadas todas as restrições que temos, hoje, para diferenciar estas escalas, falar em hibridismo ou transculturação "local", "regional" ou "nacional" não é o mesmo que falar em hibridismo continental ("latinoamericano") e, menos ainda, global, como um dos traços básicos de uma identidade mundializada.

Como parte da própria lógica "flexível" do capitalismo, só seria bom o que é móvel, efêmero, aberto à mudança e à mistura constantes (para ser consumido de novo). Mas, como já nos alertava o grande "teórico da velocidade" (ou da "dromologia"), Paul Virilio, num sentido mais amplo:

(...) sempre se diz que a liberdade primordial é a liberdade de movimento. É verdade, mas não a velocidade. Quando você vai depressa demais, você é inteiramente despojado de si mesmo, torna-se totalmente alienado. É possível, portanto, 
uma ditadura do movimento [ao que poderíamos acrescentar:

"e uma alienação do território"]. (Virilio, 1984:65)

Complementando o que indicamos há pouco, o que importa não é apenas o "estar em movimento" (embora alguns grupos sobreenfatizem essa condição), mas a possibilidade que temos de desencadear esse movimento quando precisarmos - ou, de forma mais livre, quanto quisermos - pois o fato de "a liberdade primordial" ser, como indica Virilio, "a liberdade de movimento", não significa que tenhamos de estar, obrigatoriamente, sempre, em movimento. É como se defendêssemos a mobilidade, o hibridismo e a multiterritorialidade de tal forma que eles se tornassem, assim, compulsórios. "Condenados" ao hibridismo e/ou ao trânsito entre territórios poderíamos, no extremo, perder qualquer ponto de referência mais estável, imprescindível, de certa forma, à nossa condição de humanos - humanos que não têm a "obrigatoriedade" de um mesmo comportamento sócio-territorial o tempo inteiro, até porque a imbricação entre movimento e repouso constitui uma presença permanente em nossas vidas.

É o que nos indica também, de forma ampla, esta expressão contundente de Cornelius Castoriadis:

(...) um sujeito não é nada se não for a criação de um mundo para ele numa clausura relativa. (...) Essa criação sempre é a criação de uma multiplicidade. (...) Essa multiplicidade se desenvolve sempre de dois modos: o modo do simplesmente diferente, como diferença, repetição (...) e o modo do outro, como alteridade, emergência criadora, imaginária ou poiética. (Castoriadis, 1990:248)

O discurso, dominante hoje, do hibridismo/transculturação e da multi ou transterritorialidade, ligado muitas vezes à concepção de uma mobilidade irrestrita, deve ser tomado com cautela, pois a "criação" de um novo tempo, a "emergência criadora, poiética", a que alude Castoriadis, advinda desta multiplicidade, inclui sempre, também, de algum modo, a presença de uma alteridade - e esta só pode existir no âmbito de um relativo fechamento, de "um mundo... numa clausura relativa".

Por isso, o trânsito, a transculturação e o hibridismo não ocorrem para todos e muitos menos se manifestam nas mesmas intensidades. Se para alguns grupos ou sujeitos as distâncias se comprimiram com os novos meios tecnológicos e com isso a possibilidade de trânsito por múltiplos territórios se faz cada vez mais presente, combinando diferentes modos de 
vida, para muitos outros as distâncias se tornaram proporcionalmente até maiores em relação a outros territórios que, vivendo uma espécie de "clausura", seja econômica, seja cultural e/ou política, acabam sendo "impedidos" de sair da "velha" territorialidade funcional construída entre a casa e o trabalho. Ou, ainda, em outros casos, a presença dos muros nas cidades que, aparentemente apresentam distâncias pequenas para grupos distintos, acaba provocando "distanciamentos" gigantescos em termos de relações de aproximação afetiva e mesmo de trocas e/ou mesclas culturais.

Não podemos esquecer que a tese de que vivemos - ou que devemos viver - um tempo de abertura e mobilidade indiscriminadas foi propalada também pelo economicismo neoliberal, como se fizesse parte de um paradigma inexorável: abertura de mercados, abertura - ou mesmo "fim" de fronteiras, "Estado mínimo" em suas formas de controle (que são sempre, também, territoriais), fluxos financeiros instantâneos e globalizados... A recente crise financeira global veio colocar uma pá de cal nesta boutade, defendendo-se e recorrendo-se, com toda força, a novas formas de intervencionismo estatal. $\mathrm{Na}$ verdade, bem sabemos, o próprio capitalismo vive da intercalação de momentos de maior fluidez e abertura e momentos de maior estagnação e fechamento ${ }^{21}$.

Mesmo num mundo em que a metáfora do nomadismo se tornou quase lugar- comum, a grande mobilidade e a hibridização cultural, obviamente, não regem a vida de todos - pelo contrário, o que vemos hoje é até, de certa forma, um processo inverso, com um conjunto crescente de restrições à mobilidade, principalmente no que se refere à mobilidade de pessoas, e que tende a se fortalecer diante da atual crise econômica global.

Abertura - relativa - para mudar e, assim, fortalecer nossa autonomia, é muito diferente de abertura - permanente, quase absoluta para não desenvolver laços, numa espécie de nomadismo irrefreável. Da mesma forma, fechar-se (taticamente) para resistir é muito diferente de fechar-se - indefinidamente - para se isolar e/ou como forma básica de vida. A grande questão não é optar pela abertura à transculturação, ao hibridismo "antropofágico", à multi/transterritorialidade, frente ao fechamento identitário, à mono-cultura (!) e à uni-territorialidade, até porque culturas isoladas e territórios completamente fechados, de fato, nunca existiram. Culturas completamente abertas ao intercâmbio, à

\footnotetext{
${ }^{21}$ A esse respeito, ver a interpretação de Arrighi (1996) para a história do capitalismo, especialmente entre suas concepções de "capitalismo" (em sentido estrito) e "territorialismo".
} 
hibridização, da mesma forma, nunca foram produzidas - seria como decretar, no seu extremo, o seu próprio desaparecimento. Convivem, entretanto, formas muito distintas nesse jogo de abertura e (relativo) fechamento, hibridização e (pretensa) essencialização.

Não se trata, pois, de abertura ou fechamento, de hibridismo ou essencialização. Até porque, como vimos, hibridismo e transterritorialidade não são bons ou maus em si mesmos. Eles podem ser impostos ou mais igualitariamente construídos, assim como, do mesmo modo, essencialização pode ter um caráter também "estratégico" (Spivak, 1988, 1993), enquanto momento de relativo fechamento na construção de um processo de autonomia.

No imenso rol de situações e contextos geo-históricos, desenha-se sempre a possibilidade do múltiplo - múltiplo não apenas no sentido do "viver no limite", pelas/nas fronteiras, mas também no sentido da possibilidade, sempre em aberto, de transitarmos por diferentes culturas e por diferentes territórios. Uma dessas possibilidades é aquela presente nos processos aqui tomados como "antropofagização", ao "devorarmos" outros territórios para torná-los, de alguma forma, "nossos", não por uma simples assimilação mecânica, mas pela incorporação, dialógica, de traços ou componentes que nos são mais enriquecedores. Politicamente, mais importante do que concebermos nossa vida e nossas identidades como intrinsecamente "híbridas" e "multi/transterritoriais" é a certeza de, se e quando nos aprouver, termos ao nosso dispor a alternativa de mudar de território, experimentar outras formas de identificação cultural, intercambiar valores - e que ninguém nos obrigará nem à permanente hibridização, nem à constante mobilidade dentro da enorme multiplicidade territorial do nosso tempo.

Como afirmaram Gatens e Lloyd (1999), de um lado encontra-se "a liberdade crítica para questionar e desafiar na prática nossas formas culturais herdadas; de outro, a aspiração por pertencer a uma cultura e a um lugar e, assim, sentir-se em casa neste mundo". (p. 78) Por mais transitórios que eles pareçam, precisaremos sempre construir "identidades" e "territórios" que, quase sempre fruto de misturas inusitadas, necessitam também de tempo se os quisermos "maturados", refletidos, e sua lapidação dar-se-á sempre pela constatação e/ou invenção de um Outro - mas um outro não apenas para nos reconhecer enquanto diferentes, ao transitar por "nossos" territórios, como também para conosco plenamente conviver, ao construir e praticar territórios de uso e apropriação coletivos, comuns. 
É nesse sentido que devemos falar de um espaço-tempo sempre "alter-nativo" - não só no sentido de representar uma alternativa, a criação do novo, mas também de permitir alternâncias - alternâncias entre o "Outro" (alter) e o "nativo", o mais e o menos híbrido, entre o mais e o menos aberto, enfim, um espaço-tempo que alie a permuta, a extroversão e a mobilidade com os igualmente imprescindíveis recolhimento, introspecção e repouso. E o pretenso "equilíbrio" entre essas dimensões só pode ser avaliado através do rigoroso trabalho empírico e da consideração das múltiplas necessidades e interesses em jogo para cada sujeito, grupo e/ou classe social. Assim, a "antropofagia" territorial deve ser sempre fruto de uma escolha, ou de uma estratégia, ou até mesmo de uma fuga, no sentido libertário das "linhas de fuga" deleuzeanas, não se configurando nunca como uma imposição ou obrigatoriedade.

No dizer do grande poeta Manoel de Barros:

É preciso transver o mundo.

\section{TRANSTERRITORIALIDADE E ANTROPOFAGIA: TERRITORIALIDADES DE TRÂNSITO NUMA PERSPECTIVA BRASILEIRO-LATINO-AMERICANA}

Resumo: Num mundo globalizado como o nosso a construção identitária e territorial se torna cada vez mais complexa, mesclando multiplicidade territorial, transculturação e hibridismo com fechamentos culturais "essencializadores". Os processos de territorialização marcados pela multiterritorialidade podem ser associados, no caso latino-americano e, especialmente, brasileiro, àquilo que propomos denominar de uma transterritorialidade "antropofágica", capaz de assimilar e transformar a territorialidade do Outro. Todos esses processos têm profundas implicações políticas, não se tratando, a priori, de uma "boa" abertura ou de um "mau" fechamento cultural e territorial.

Palavras-chave: hibridismo cultural, antropofagia, transterritorialidade.

\section{TRANSTERRITORIALITY AND ANTHROPOPHAGY: TRANSIT TERRITORIALITIES IN A LATIN-AMERICAN POINT OF VIEW}


Abstract: In a globalized world like ours, building identities and territories becomes much more complex, by a mixture of territorial multiplicity/transculturation/hybridism and "essencializing" cultural enclosures. The processes of territorialization characterized by multiterritoriality can be associated, specially in Latin America and, more specifically, Brazil, to what we propose to call "anthropophagic" transterritoriality, the capability to assimilate and transform Other's territoriality. All these process have huge political implications and do not mean just, a priori, a "good" openness or a "bad" cultural and territorial closure.

Keywords: cultural hybridism, anthropophagy, transterritoriality.

\section{BIBLIOGRAFIA}

AGUIAR, F. e VASCONCELOS, S. (2004). O conceito de Transculturação na obra de

Angel Rama. In: Abdala Jr., B. (org.) Margens da Cultura: Mestiçagem, Hibridismo

\& outras misturas. Boitempo. São Paulo.

ANDRADE, O. (1995). A Utopia Antropofágica. $2^{a}$ ed. Globo. São Paulo. APPADURAI, A. (1997). Soberania sem territorialidade. Novos Estudos 49.

ARRIGHI, G. 1996 (1994). O longo século XX. Contraponto. Rio de Janeiro; EdUNESP. São Paulo.

BHABHA, H. (1998). O local da cultura. EdUFMG. Belo Horizonte.

BOURDIEU, P. (1989). O Poder Simbólico. Difel. Lisboa; Bertrand Brasil. Rio de Janeiro.

BURKE, P.( 2003). Hibridismo Cultural. Editora da Unisinos. São Leopoldo.

CANCLINI, N. (1998) (1989) Culturas Híbridas. Editora da USP. São Paulo.

CASTORIADIS, C. (1990). Le Monde Morcelé: les carrefours du labyrinthe III. Seuil. Paris.

COSFROGEL, R. (2010). Para descolonizar os estudos de economia política e os estudos pós-Coloniais: transmodernidade, pensamento de 
fronteira e colonialidade global. In: Sousa Santos, B. e Meneses, M. (org.) Epistemologias do Sul. Cortez. São Paulo.

FOUCAULT, M. (1984). Sécurité, Territoire, Population. Gallimard. Paris . Ed. brasileira: (2008) Segurança, Território, População. Martins Fontes. São Paulo. 1979. Microfísica do Poder. Graal.Rio de Janeiro.

FREYRE, G. (1998) (1933). Casa-Grande \& Senzala. Record. Rio de Janeiro.

GATENS, M. e LLOYD, G. (1995). Collective Imaginings: Spinoza, Past and Present. Routledge. Londres e Nova York:

GLISSANT, E. (2005) (1996). Introdução a uma poética da diversidade. Editora da UFJF. Juiz de Fora:

GOETTERT, J. e MONDARDO, M. (2009). O "Brasil migrante": gentes, lugares e transterritorialidades. GEOgraphia n. 21. PPGEO. Niterói.

GOMES, H. G. (2005). Antropofagia. In: FIGUEIREDO, Eurídice (org.). Conceitos de cultura e literatura. UFJF. Juiz de Fora.

GONZÁLEZ-CASANOVA, P. (1965). Internal Colonialism and National Development.

Studies in Comparative International Development 1, n. 4.

HAESBAERT, R. (2011). Viviendo en el límite: los dilemas del hibridismo y de la multi/

transterritorialidad. In: Zusmán, P. et al. (org.) Geografias Culturales: aproximacio-

nes, intersecciones y desafíos. Fac. de Filosofía y Letras da UBA. Buenos Aires

GEOgraphia $\mathrm{n}$.

(2007). Território e Multiterritorialidade: um debate.

17. Programa de Pós-Graduação em Geografia. Niterói.

Janeiro. (2004). O Mito da Desterritorialização. Bertrand Brasil. Rio de (2002). Territórios Alternativos. Contexto. Campinas; EdUFF. Niterói. do IX Encontro

(2001). Da desterritorialização à Multiterritorialidade. In: Anais Nacional da ANPUR. ANPUR. Rio de Janeiro. 
(1996). O binômio território-rede e seu significado políticocultural. In: A Geografia e as transformações globais: conceitos e temas para o ensino (Anais do Encontro "O ensino da Geografia de $1^{o}$ e $2^{\circ}$ Graus frente às transformações globais”). UFRJ. Rio de Janeiro. HELENA, L. (1983). Uma literatura antropofágica. UFC. Fortaleza. HUNTINGTON, S. (1997). O choque das civilizações e a recomposição da ordem mundial. Objetiva. Rio de Janeiro.

JÁUREGUI, C. (2005). Canibalia: canibalismo, calibanismo, antropofagia cultural y

Consumo en América Latina. Casa de las Américas. Havana e Córdoba.

KRANIAUSKAS, J. (1992). Hybridism and Reterritorialization. Travesía vol. 1, n. 2.

LACOSTE, Y. (1988). A Geografia - isso serve, em primeiro lugar, para fazer a guerra.

Papirus. Campinas.

LOPES, L. e BASTOS, L. (org.) (2010). Para além da identidade: fluxos, movimentos $e$

trânsitos. Editora da UFMG. Belo Horizonte.

LUSSAULT, M. (2007). L'Homme Spatial. Seuil. Paris.

MALTZ, B. (1993). Antropofagia: rito, metáfora e pau-brasil. In: Maltz, B.; Teixeira, J. e

Ferreira, S. Antropofagia e Tropicalismo. Editora da UFRGS. Porto Alegre.

MASSEY, D. (2008). Pelo espaço: uma nova política da espacialidade. Bertrand Brasil. Rio de Janeiro.

(2007). Filosofia e Política da Espacialidade: algumas considerações. GEOgraphia n.12. Programa de Pós-Graduação em Geografia. Niterói.

(1995). Thinking radical democracy spatially. Environment and Planning D: Society \& Space 13.

(1994). A global sense of place. In: Space, Place and Gender. University of Minnesota Press. Minneapolis.

McEWAN, C. (2008). Transnationalism. In: Duncan, J. et al. (org.) A Companion of

Cultural Geography. Blackwell. Oxford. 
MIGNOLO, W. (2003). Histórias locais / Projetos Globais: colonialidade, saberes

subalternos e pensamento liminar. Editora da UFMG. Belo Horizonte.

MONDARDO, M. (2009). Os períodos das migrações: territórios e identidades em Francisco Beltrão/PR. Dissertação de Mestrado. Programa de Pós-Graduação em Geografia, Universidade Federal da Grande Dourados. Dourados.

MOREIRAS, A. (2001). A exaustão da diferença: a política dos estudos culturais latino-

americanos. EdUFMG. Belo Horizonte.

MUNANGA, K. (2010). Mestiçagem como símbolo da identidade brasileira. In: Sousa Santos, B. e Meneses, M. (org.) Epistemologias do Sul. Cortez. São Paulo.

ORTIZ, F. (1999) (1940). Contrapunteo cubano del tabaco y el azúcar. Madri. EdiCubaEspaña.

RAMA, A. (2007). Transculturación narrativa en América Latina. Ediciones El Andariego. Buenos Aires).

RAFFESTIN, C. (1993) (1980). Por uma Geografia do poder. Ática. São Paulo.

REVEL, J. (1998). Jogos de Escalas. Fundação Getúlio Vargas Editora. Rio de Janeiro.

RIBEIRO, D. (1995). O povo brasileiro. $2^{\mathrm{a}}$ ed. Companhia das Letras São Paulo.

SACK, R. (1986). Human Territoriality: its theory and history. Cambridge University Press. Cambridge.

SAYAD, A. (1998). A imigração ou os paradoxos da alteridade. EdUSP. São Paulo.

SCHILLER, N.; BASCH, L. e SZANTON, C. (1995). From immigrant to transmigrant: theorizing transnational migration. Anthropological Quarterly 68.

SPIVAK, G. (1993). Can the subaltern speak? In: Patrick Williams e Laura Chrisman (eds.), Colonial Discourse and Post-Colonial Theory: $a$ Reader. Harvester Wheatsheaf. Hemel Hemsptead.

(1988). Subaltern Sudies: Deconstructing Historiography. In:

Guha, R.; Spivak,

G. (org.) Selected Subaltern Studies. Oxford University Press. Nova York. 
STAM, R. (1999). Palimpsestic Aesthetics: a meditation on hibridity and garbage. In: May, J. e Tink, J. Performing Hibridity. Univ. of Minnesota Press. Minneapolis e Londres.

TOMLINSON, J. (1999). Globalisation and Culture. Chicago: Chicago University Press.

VIRILIO, P. (1984). Guerra Pura. Brasiliense. São Paulo.

YOUNG, R. (2005) (1995) O Desejo Colonial. Perspectiva. São Paulo. 